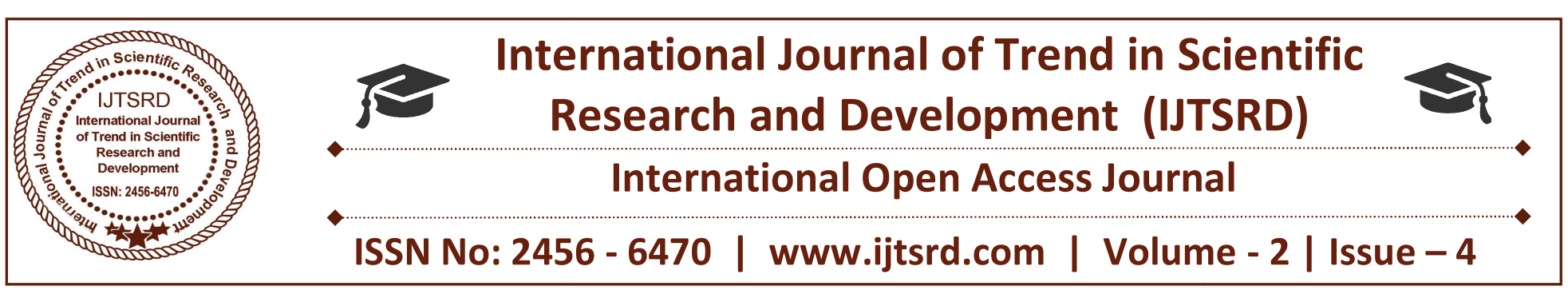

\title{
An Investigative Review on Landing Gear of an Aircraft Structure based on Finite Element Monitoring
}

\author{
Dr. K S Ravi, Dr. G V Naveen Prakash, Dr. K B Vinay, \\ Dr. S A Mohan Krishna, Naveen Ankegowda
}

Dept. of Mechanical Engineering, Vidyavardhaka College of Engineering, Mysuru, Karnataka, India

\section{ABSTRACT}

Landing gear is the critical subsystem of an aircraft. The need is to design the landing gear with minimum weight \& volume, high performance, improved life \& reduced life cycle cost. Further, it is essential to reduce the landing gear design and development cycle time while meeting all the regulatory \& safety requirements. This includes the design and analysis of a medium size transport aircraft landing gear unit. A typical landing load case will be assumed for which structural analysis will be carried out. During landing, there will be three different types of loads viz., vertical load, drag load \& side load. Each of these loads will cause axial compression, bending and torsion on the strut of the landing gear. It also absorbs the energy from the impact of landing numerical type simulation has become highly invaluable tool for the assessment of the landing gear type dynamics also as well as of aircraft landing structure gear interaction. This paper also describes the normal structure review of a simple landing-gear structure model system, and which is accurately simulates with the energy system absorbed by the gear without the adding substantial structure and complexity with the model. it carries the structure aircraft weight at all require ground operations, including, landing, take off, taxiing, and towing. Many type model includes nonlinear structure effects such as a velocity type squared related high damping, poly tropic gas law, stick-slip friction, a geometry governed with the high model structure for the high discharge type coefficients and methods, effects a nonlinear spring and damping model structure.
Keywords: Landing Gear; Simulation; Analysis; Finite Element Monitoring; Dynamics.

\section{INTRODUCTION}

One of the issues confronting from the aircraft industry is landing gear apparatus reproduction, simulation and design and analysis, particularly shimmy and rigging type gear, brake induced vibration structure. Although neither shimmy nor gear brake incited vibrations framework structure are typically catastrophic, circle framework they can lead to accidental condition because of unnecessary weight, wear and shortened existence of apparatus parts and structure and add to pilot and passenger discomfort. Recently, space science agency has started a push to build the safety by a component of diverse many years. This security activity has prodded a numerous enthusiasm for enhancing landing rigging outline framework to minimize brake-instigated vibration that are still generally misunderstood phenomenon. The significant center of the proposition is to condense work recorded from the diverse years to highlight the most recent landing gear in taking care of these vibration issues in aviation. Characterization and required validation and of shimmy and highly brake-induced vibration system of aircraft landing gear are also reported with many goals $[1-4]$.

The landing gear is an important system for the aircraft. It also absorbs the energy of the landing 
impact that is related to the ground and operations, including take off, taxiing, and towing structure. Numerical simulation has become an invaluable important tool for the assessment of landing gear system as well as of aircraft/landing gear interaction. Recent advances in different computational type speed have made an aircraft and spacecraft crash structure and its simulations using an explicit, and nonlinear, transient-dynamic system. Finite Element Monitoring (FEM) gives the development of a simple type landing-gear model structure, which accurately simulates the energy which absorbed by the gear system without adding substantial type Complexity to the model. A crash model that the landing gear response is require approximated with a spring structure, where the force applied to the engine fuselage is also computed in a user-written type subroutine. Aircraft and Helicopter crash simulations using this approach are compared to and also it is necessary with the previously acquired experimental type data from a full-scale type crash test of a composite manufactured helicopter [3-6].

It is important to decide static and element ground loads for the aircraft structure ground moves precisely in the outline design stage. Simulation of the critical operational cases is a better route that contrasted with the tests on real aircraft to the large examination heaps at a sensible expense. The simulation and reproduction of landing gear and ground moves for different transport carrier is can be introduced and better route that contrasted with the tests on real aircraft to the large examine these heaps at a sensible expense. The flying machine models can be manufactured by the multibody multiplication, reproduction device SIMPACK. The model realized in joins horizontally even components of the model. Cornering, burden runs and pushback are as ordinary ground moves. For entertainment of braking, a fundamental However correct Antilock Braking System (ABS) calculation is essential. Shimmy vibration is a fundamental and essential for the development in the landing gear structure either the Takeoff or landing of an aircraft and flying machine. This sort of vibration is given from the dynamic phase of the forward development of the airplane. In this manner, this condition begins a restraint empowered sort of vibration in the wheels that may be achieved.

Weariness, corrosion, fatigue can be observed to be the primary components and mechanisms. Plan structure lacks and assembling imperfections drove predominantly to fatigue while poor material choice and improve its field upkeep were the principal starting points of corrosion related failures. Thus, a series of preventive measures was either prescribed or re-stressed. While weariness and fatigue can best be tended to by enhancing the nature of assembling and by better describing in-service and assembling and by, much work stays to be done on the timedependent with the degradation process and their synergism with fatigue, as consumption has regularly been neglected in both the configuration, design and testing stages and additionally in the support domain. Despite the broad arrival landing gear outline, design and tests completed by the fashioners and the large makers, and the huge number of inconvenience with travel free arrivals accumulated by the users, the Canadian Forces (CF), and also others, have experienced a large scope of issues or range a disappointments with landing gear systems [5-8].

\section{FINITE ELEMENT MONITORING OF AIRCRAFT LANDING GEAR}

Finite Element Monitoring can be employed to model tooth avoidances and contact examples between both metallic and non-metallic gear. The initial phase in assessing tooth diversion, deflection and hence load sharing is to demonstrate the model tooth contact. Since, the FEM reproduces the real cross section of the tooth, it can be utilized to decide burden offering to assembling mistakes. At long last, the greatest twisting anxieties can be resolved. For forecast of the torsional network solidness three its stages were considered: investigation with incomplete teeth models, examination with single-tooth apparatus model and investigation of multi teeth gears over a complete cross section cycle. The expectation of gear element loads and it is dependably a noise before you start to for the substance as a different content document. These elements are identified with the gear transmission mistake which is characterized as the distinction between the positions that the yield shaft of a gear drive would have if the gearbox was great.

The transmission mistakes are brought about by the tooth geometry blunders, versatile disfigurements, and flawed mounting. Extraordinary limited components have been created to model twisting, and torsional disfigurements where different sorts of assembling structure and gathering of the apparatuses are considered. The contact connection between two gear the produces mechanical loads between associating bodies that can influence their working 
conditions. The recognizable proof of the contact locale is the initial phase in contact investigation issues. A contact identification calculation relies on upon the limit estimate of contact questions and can be for instance, straight lines between hubs, limited component shape capacities, spline capacities or uncommon procedures (i.e. pinball calculation). The outline of riggings comprises as a rule of two sections: worldwide and nearby (tooth geometry) apparatus plan. The outline of the nearby tooth geometry is imperative. The shape, size and position of the contact spot are the central point in giving smooth operation of the rigging pair. FEM is a powerful investigation instrument, will give sensible results to the rigging conduct. To upgrade the exactness of the examination a rehashed effect brought about by element variances of the apparatus torque can be considered $[6-12]$. The heap conveying limit and administration life are the essential prerequisites in the configuration of riggings. There are four primary disappointment modes in gear frameworks: tooth bending weariness, contact fatigue, scoring and surface wear.

\section{EXPERIMENTS AND ANALYSIS FOR AIRCRAFT LANDING GEAR}

Transport aircraft can be arranged with information frameworks for hardware, flight controls, and other basic subsystems. As, an expanded emphasis has been put on the potential for utilizing these information capacities, in conjunction with rising sensor and innovations for checking of flying machine condition during flight. The potential advantages of fiber optic sensors include the capacity to access limited or shortened areas where it is hard to investigate and also permitting a circulation of sensors at areas around the aircraft. A specific test can be arranged such that the sensors for operation on aircraft parts that experience development or turn during use. Twenty-six FabretPerot Interferometer strain sensors and two long period grinding (LPG) moisture sensors can be introduced on the principle gear assembly. The strain readout frameworks can be prepared to do either simple or advanced digital to a PC for 5 channels, but it is the (24 MUX-8) switched type channels also capable of only digital type output. The gear can be subjected to cyclic structure loading using a full-scale shaker type table apparatus at NASA Langley Research Center.

The work structures a portion of a bigger examination concerning split location utilizing acoustic outflow
(AE) amid landing apparatus airworthiness testing. It concentrates on the utilization of key part examination (PCA) to separate between weakness split engendering (FCP) signs and elevated amounts of foundation commotion. A simulated AE crack source was produced and also five sources were utilized to create contrasting manufactured AE signals. Signs were recorded from each of the six fake sources in a genuine landing rigging part subject to no heap. This extends past work utilizing essential part examination (PCA) of AE highlight information for sign discrimination. PCA is a technique used to streamline high-arrange information sets to lower measurements to permit a basic investigation. Basically the information are analyzed in multi-dimensional space and the two bearings of most prominent difference (not as a matter of course in accordance with any of the information measurements), or the vital parts, are recognized. The information can then be displayed as a two dimensional $\mathrm{x}-\mathrm{y}$ plot as far as the two key segments. The foremost segments are distinguished utilizing the philosophy laid out underneath [11 - 15].

\section{SUMMARY}

An inventive landing gear modelling methodology depends in a crash simulation of a full-scale accident test of a composite helicopter. The simulation procedure was using the basic arrival gear model with an unbending and exact model. Helicopter crash design and simulation utilizing this methodology were contrasted and procured test information from a fullscale accident test of a composite helicopter. The accompanying conclusions will be accomplished come to if the project will effectively finished The landing gear demonstrating, design and modelling will be approach precisely recreated with the extent and introduction of the landing gear power on the model. The utilization of an unbending rigid model for a part of the simulation will be suitable and brought about critical lessening of CPU time for the aggregate accident recreation and examination. Synoptically, the arrival landing gear model will be fruitful at approximating the impact of the stroking without adding significantly to the model unpredictability. This rearrangement in conjunction with the inflexible model assumption can bring about huge significant reduction in time.

\section{REFERENCES}

1. Pritchard, J. (2001). Overview of landing gear dynamics . Journal of aircraft, 38(1), 130-137. 
2. Krüger, W., Besselink, I., Cowling, D., Doan, D. B., Kortüm, W., \& Krabacher, W. (1997), Aircraft landing gear dynamics simulation and control. Vehicle System Dynamics, 28(2-3), 119-158.

3. Lyle, K. H., Jackson, K. E., \& Fasanella, E. L. (2002), Simulation of aircraft landing gears with a nonlinear dynamic finite element code. Journal of Aircraft,39(1), 142-147.

4. Quayle, A. R., Dowling, A. P., Babinsky, H., Graham, W. R., \& Sijtsma, P. (2009), Landing gear for a silent aircraft (Doctoral dissertation, University of Cambridge).

5. Daniels, J. N. (1996), A method for landing gear modeling and simulation with experimental validation (Master's thesis, George Washington University.

6. Anurag Dubey, Vamsi Krishna Undavalli, Shri Shashwat Gupta \& Balakrishna Bodramoni (2015), Landing gear of an aircraft structure, (Amity University, Noida, Uttar Pradesh, India)

7. Kilner, J. R. (1982), Pneumatic tire model for aircraft simulation. Journal of Aircraft, 19(10), 851-857.

8. Prášil, L., \& Mackerle, J. (2008), Finite element analyses and simulations of gears and gear drives: A bibliography 1997- 2006. Engineering computations, 25(3), 196-219.

9. Freymann, I. R. (1991). Actively damped landing gear system. AD-A239 914, 16.

10. Prevey, P., Jayaraman, N., Ontko, N., Shepard, M., Ware, R., \& Coate, J. (2004), Mechanical Suppression of SCC and Corrosion Fatigue Failures in 300M Steel Landing Gear. LAMBDA TECHNOLOGIES CINCINNATI OH.

11. Kraft, D. C. (1968), ANALYTICAL LANDING GEAR-SOILS INTERACTION-PHASE 1. DAYTON UNIV OH RESEARCH INST.

12. Eaton, M. J., Pullin, R., Hensman, J. J., Holford, K. M., Worden, K., \& Evans, S. L. (2011), Principal component analysis of acoustic emission signals from landing gear components: an aid to fatigue fracture detection. Strain, 47(s1), e588-e594.

13. Lopes, L. V. (2009), A new approach to complete aircraft landing gear noise prediction (Doctoral dissertation, The Pennsylvania State University).

14. Kushida, Y., Hara, S., Otsuki, M., Yamada, Y., Hashimoto, T., \& Kubota, T. (2013), Robust landing gear system based on a hybrid momentum exchange impact damper. Journal of Guidance, Control, and Dynamics, 36(3), 776789.

15. Denery, T., Ghidella, J. R., Mosterman, P. J., \& Shenoy, R. (2006), Creating Flight Simulator Landing Gear Models Using Multidomain Modeling Tools. InAIAA Modeling and Simulation Technologies Conference and Exhibit (p. 6821). 